\title{
The Comparative Study of Laser-MAG Hybrid Welding and MAG Welding of Atmospheric corrosion resistant steel SMA490BW
}

\author{
Xiangyang $\mathrm{Wu}^{1,2, a}$, Zhiyi Zhang ${ }^{1,2, \mathrm{~b}}$, Weihua Zhang ${ }^{2, \mathrm{c}}$, \\ Weilin Chen ${ }^{2, d^{*}}$, Yong Chen ${ }^{2, e}$ \\ ${ }^{1}$ CSR Qingdao Sifang Co., Ltd. Qingdao, 266000, China \\ ${ }^{2}$ Southwest Jiaotong University, Chengdu 610031, China \\ asfxiangyangw@163.com, byefan_0954@163.com, 'tpl@swjtu.edu.cn, \\ dyefan_0954@163.com, e276074724@qq.com
}

\begin{abstract}
Keywords: Atmospheric corrosion resistant steel SMA490BW; Laser-MAG hybrid welding; welding procedure; residual stress

Abstract. In view of the problems like incomplete penetration caused by the traditional MAG welding, laser-MAG hybrid welding of $12 \mathrm{~mm}$ thick corrosion resistance steel was studied by using the SMA490BW as the research object, which was the material of high speed train bogie. By comparing weld formation, residual stress, microstructure of $12 \mathrm{~mm}$ thick corrosion resistance steel welding joints welded by MAG welding and laser-MAG hybrid welding, the following results can be get. The residual stress value in atmospheric corrosion resistant steel SMA490BW welding joint of laser-MAG hybrid welding was smaller than that of MAG welding; the weld appearance quality of hybrid welding was better than that of MAG welding, and the weld microstructure of hybrid welding was much more uniform and fine; the hardness value of the weld zone welded by hybrid welding was higher than that of MAG welding, but the width of heat affect zone was smaller than that of MAG welding.
\end{abstract}

\section{Introduction}

The rapid development of high-speed railway in China has made great achievements in recent years. The total operations mileage of China's high-speed railway was more than $16000 \mathrm{~km}$ until December 28,2014 . The operating mileage of high-speed railway in China taken up about $50 \%$ of the world, which was the best in the world high-speed railway mileage list. With the improvement of the running speed, the load and operating conditions of bogie were becoming more and more complex [1]. As an important part of the train, the bogie is mainly used to support the body, motor and other components. The bogie was suffering the horizontal stress, vertical stress and other complex stress while the movement and steering of the train. Therefore the safety and stability of the train was determined by the welding quality of bogie [2]. Under the effect of the factors like stress concentration, fracture accident of the bogie caused by fatigue failure was often occurred, which has caused great restriction for the high-speed and stable operating [3,4]. Therefore the material selection, welding procedure and the service performance of the bogie has become important research topics [5].

As for the bogie, the common welding method is MAG arc welding. The value of residual stress is relatively large and it's easy to deform, causing the incomplete penetration defect easily, which will lead to serious stress concentration. Therefore it is not conductive to the reliability and safety of the bogie frame [6]. In order to solve the incomplete penetration defect and stress concentration, the laser-MAG hybrid welding was considered. With the advantages of high power density, small heat input, large weld penetration, better gap adaptive capacity and high speed welding, the laser arc hybrid was of great importance to solve the problems of the bogie frame [7, 8].

In this paper, the processing property of the atmospheric corrosion resistant steel SMA490BW was studied, which is used in high-speed train bogie and welded by laser-MAG hybrid welding, attempting to give better processing parameters of the $12 \mathrm{~mm}$ thick corrosion resistance steel SMA490BW in laser-MAG hybrid welding. Besides the influences of MAG welding and laser-MAG hybrid welding on 
the weld formation and residual stress distribution were analyzed, which provided theoretical guidance for the design of actual bogie structure and welding production.

\section{Material and Experiments}

Testing Material. The $12 \mathrm{~mm}$ thick atmospheric corrosion resistant steel SMA490BW was used as the testing material, according to the Japanese standard JIS G3114. The chemical composition of atmospheric corrosion resistant steel SMA490BW is shown in Table 1.

\begin{tabular}{cccccccc}
\hline Testing Material & $\mathrm{C}$ & $\mathrm{Si}$ & $\mathrm{Mn}$ & $\mathrm{P}$ & $\mathrm{S}$ & $\mathrm{Cu}$ & $\mathrm{Cr}$ \\
\hline SMA490BW & 0.18 & 0.55 & 1.40 & 0.035 & 0.035 & $0.20 \sim 0.35$ & $0.30 \sim 0.55$ \\
\hline
\end{tabular}

Table 1 The chemical composition of atmospheric corrosion resistant steel SMA490BW ( wt\% )

In addition to the elements in the above table, the atmospheric corrosion resistance elements like $\mathrm{Mo}, \mathrm{Ti}, \mathrm{Ni}, \mathrm{V}$ and $\mathrm{Zr}$ were also added. Through the solid solution strengthening and fine grain strengthening of the alloy elements, the strength and plasticity of materials can be improved. At the same time, the elements like $\mathrm{Cu}, \mathrm{P}$ and $\mathrm{Ni}$ were reacted with matrix, producing dense protective film on the surface of the matrix, which improved the corrosion resistance of the material effectively.

The welding wire $\mathrm{CHW}-55 \mathrm{CNH}$ with a diameter of $1.2 \mathrm{~mm}$ was used as the weld filling material. This kind of welding wire can be used in the welding of rail vehicles and bridge structure in the condition of argon gas. The chemical composition of the welding wire CHW-55CNH is shown in Table 2 .

\begin{tabular}{lcrrrrrrrr}
\hline $\begin{array}{l}\text { Testing } \\
\text { Material }\end{array}$ & $\mathrm{C}$ & $\mathrm{Si}$ & $\mathrm{Mn}$ & $\mathrm{P}$ & $\mathrm{S}$ & $\mathrm{Cu}$ & $\mathrm{Cr}$ & $\mathrm{Ni}$ & $\begin{array}{l}\text { Othe } \\
\mathrm{r}\end{array}$ \\
\hline $\mathrm{CHW}-55 \mathrm{CNH}$ & 0.08 & 0.545 & 1.40 & 0.012 & 0.008 & 0.25 & 0.65 & 0.35 & $\leq 0.3$ \\
\hline
\end{tabular}

Table 2 The chemical composition of welding wire CHW-55CNH ( wt\% )

Experiments. The laser-MAG hybrid welding system was mainly composed by the fiber laser IPG YLS-4000, pulsed-current welding machine KEMPPI KempArc-450 and the robot ABB IRB2600. As is shown in Fig.1a, the composite form of the laser head and MAG welding torch was in the position relation as the laser head was in front while the welding torch was in the rear. In order to prevent the laser head from splashing, dust and other pollutions, the ordinary argon was used for the protection of laser head in the laser-MAG welding; the $80 \%$ Ar and 20\% CO2 were provided by welding torch for the protection of the weld pool in order to ensure the quality of weld metal.

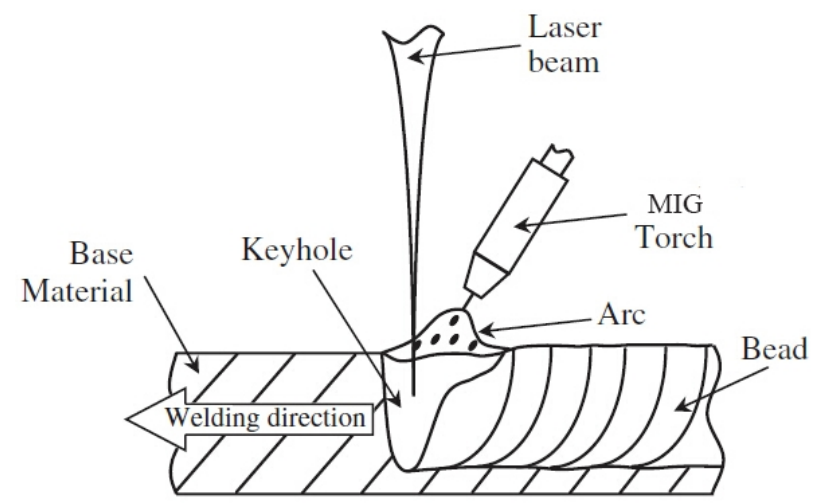

Fig. 1 Main composition of hybrid welding

The atmospheric corrosion resistant steel SMA490BW plate with the size of $300 \mathrm{~mm} \times 300 \mathrm{~mm} \times 12 \mathrm{~mm}$ was used for the test. The $30^{\circ}, 40^{\circ}$ and $60^{\circ}$ were designed as the groove angle of three kinds of butt joints (the hybrid welding groove blunt edge was $3 \mathrm{~mm}$, and the MAG welding groove blunt edge was $2 \mathrm{~mm}$ ), as is shown in Fig.2. Besides, the welding methods were MAG welding 
and laser-MAG hybrid welding. Meanwhile, the Proto iXRD residual stress measuring instrument was used to measure the residual stress; the residual stress distributions of the welded joints with different groove sizes were compared and analyzed, which were welded by different methods. As for the typical joints welded by two kinds of welding methods, the microstructure was observed through the Zeiss microscope A1m. Meanwhile, the hardness test of the joints was completed through the digital Vickers hardness tester HVS-30.

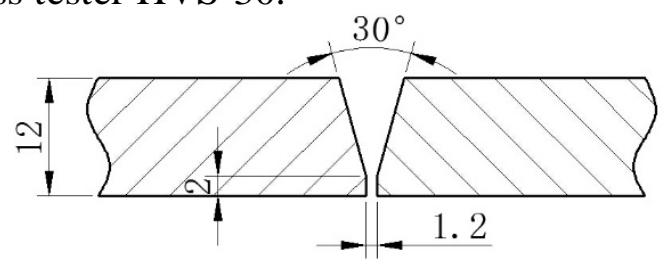

(a) MAG welding with $30^{\circ}$ groove angle

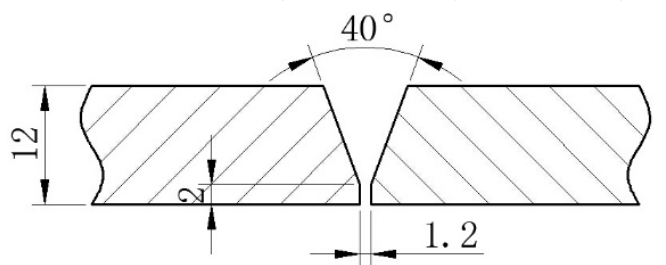

(c) MAG welding with $40^{\circ}$ groove angle

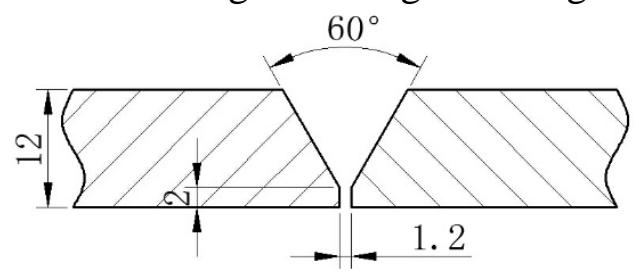

(e) MAG welding with $60^{\circ}$ groove angle

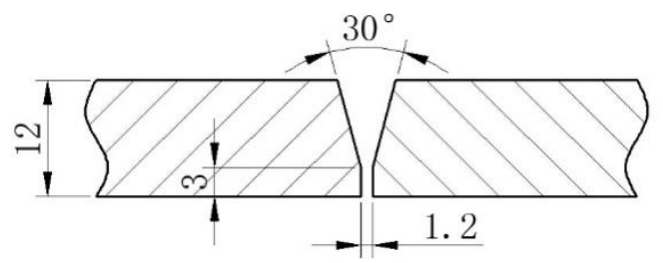

(b) Hybrid welding with $30^{\circ}$ groove angle

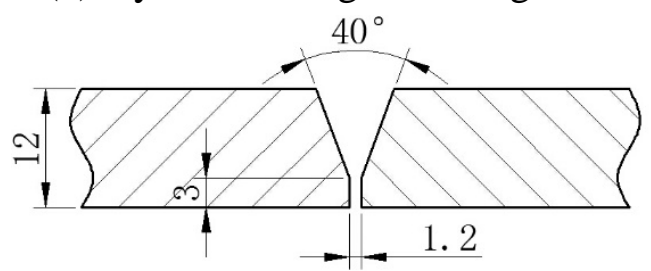

(d) Hybrid welding with $40^{\circ}$ groove angle

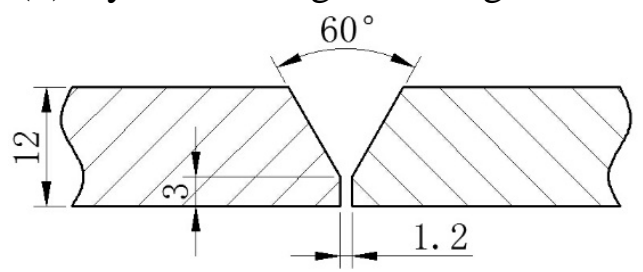

(f) Hybrid welding with $60^{\circ}$ groove angle

Fig. 2 The groove design of MAG welding and hybrid welding for butt-cover plate

\section{Results and Discussion}

Welding Test. As for the different welding methods and groove designs, the good appearance of weld formation was got by adjusting the main welding parameters like laser power $\mathrm{P}$, welding speed $\mathrm{V}_{1}$ and wire feeding speed $V_{2}$ (other parameters, the welding wire stem elongation $1=20 \mathrm{~mm}$, the distance between welding wire and laser $\mathrm{d}=2 \mathrm{~mm}$, defocusing distance $\mathrm{f}=0 \mathrm{~mm}$ ). The welding process parameters used in the experiment are shown in Table 3, where $\mathrm{H}$ stands for the laser-MAG hybrid welding, and M stands for the MAG welding. 


\begin{tabular}{cccccccc}
\hline $\begin{array}{c}\text { Welding } \\
\text { times and } \\
\text { layers }\end{array}$ & $\begin{array}{c}\text { Welding } \\
\text { speed } \\
V_{1}(\mathrm{~m} / \mathrm{min})\end{array}$ & $\begin{array}{c}\text { Wire feeding } \\
\text { speed } \\
V_{2}(\mathrm{~m} / \mathrm{min})\end{array}$ & $\begin{array}{c}\text { Laser } \\
\text { power } \\
P(\mathrm{~kW})\end{array}$ & $\begin{array}{c}\text { Current } \\
I(\mathrm{~A})\end{array}$ & $\begin{array}{c}\text { Voltage } \\
U(\mathrm{~V})\end{array}$ & $\begin{array}{c}\text { Line } \\
\text { energy } \\
Q(\mathrm{~kJ} / \mathrm{cm})\end{array}$ & $\begin{array}{c}\text { groove } \\
\text { angle } \\
\left({ }^{\circ}\right)\end{array}$ \\
\hline H30-1 & 0.48 & 8.0 & 3.5 & 205 & 24.5 & 8.46 & 30 \\
H30-2 & 0.78 & 11.5 & 1.0 & 275 & 29.5 & 5.68 & \\
H40-1 & 0.48 & 8.0 & 3.5 & 205 & 24.5 & 8.46 & \\
H40-2 & 0.78 & 11.5 & 1.0 & 275 & 29.5 & 5.68 & 40 \\
H40-3 & 0.78 & 11.5 & 1.0 & 275 & 29.5 & 5.68 & \\
H60-1 & 0.48 & 8.0 & 3.5 & 205 & 24.5 & 8.46 & \\
H60-2 & 0.78 & 11.5 & 1.0 & 275 & 29.5 & 5.68 & 60 \\
H60-3 & 0.78 & 11.5 & 1.0 & 275 & 29.5 & 5.68 & \\
H60-4 & 0.78 & 11.5 & 1.0 & 275 & 29.5 & 5.68 & \\
\hline M30-1 & 0.42 & 8.0 & $/$ & 210 & 25.0 & 6.00 & 30 \\
M30-2 & 0.48 & 10.0 & $/$ & 265 & 28.5 & 7.55 & \\
M40-1 & 0.42 & 8.0 & $/$ & 210 & 25.0 & 6.00 & \\
M40-2 & 0.48 & 10.0 & $/$ & 265 & 28.5 & 7.55 & 40 \\
M40-3 & 0.48 & 10.0 & $/$ & 265 & 28.5 & 7.55 & \\
M60-1 & 0.42 & 8.0 & $/$ & 210 & 25.0 & 6.00 & \\
M60-2 & 0.48 & 10.0 & $/$ & 265 & 28.5 & 7.55 & 60 \\
M60-3 & 0.48 & 10.0 & $/$ & 265 & 28.5 & 7.55 & \\
M60-4 & 0.48 & 10.0 & $/$ & 265 & 28.5 & 7.55 & \\
\hline
\end{tabular}

Table 3 The welding parameters of MAG welding and laser-MAG hybrid welding for the Atmospheric corrosion resistant steel SMA490BW

The heat input of the weld was calculated according to the formula given by reference [9],

$$
\mathrm{Q}=\mu_{1} \frac{\mathrm{P}}{\mathrm{V}_{1}}+\mu_{2} \frac{\mathrm{UI}}{\mathrm{V}_{1}}
$$

where $\mathrm{P}$ is laser power $(\mathrm{kW}) ; \mu_{1}$ is laser coefficient of thermal efficiency, and the value is $0.9 ; \mu_{2}$ is arc coefficient of thermal efficiency, and the value is 0.8 .

The calculation results of the welding line energy are shown in Table 3. According to the results, the heat input value of other welding beads of hybrid welding was smaller than that of MAG welding. However, the heat input value of backing welding in hybrid welding was relatively large. As for such complete weld of $12 \mathrm{~mm}$ thick SMA490BW, the total heat input value of hybrid welding was lower than that of MAG welding, which had a very avital effect on the microstructure and properties of the hybrid welding joints.

In order to compare the macro molding differences of the joint with different grooves and welded by different methods, the metallographic specimens from the welded steel plate was got, then the grinding, polishing, corrosion, observation processes and the analysis of macro morphology of the weld cross section were conducted, which is shown in Fig.3. 


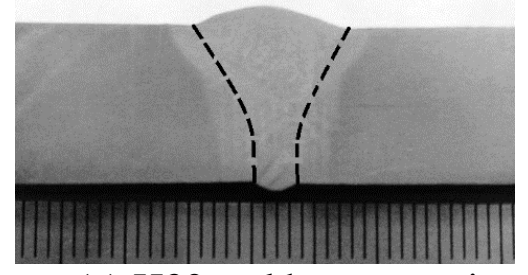

(a) H30 weld cross section

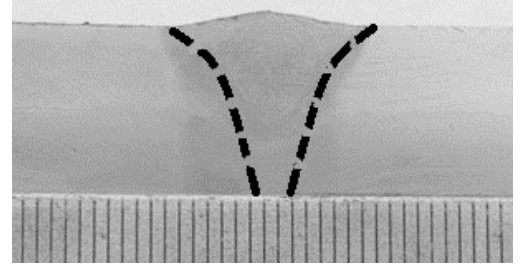

(c) H40 weld cross section

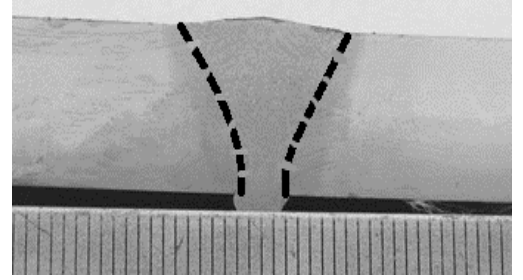

(e) H60 weld cross section

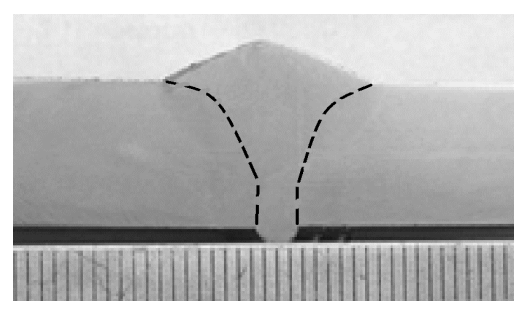

(b) M30 weld cross section

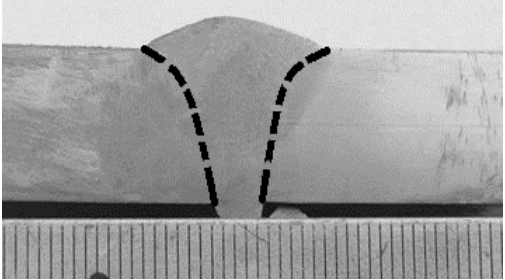

(d) M40 weld cross section

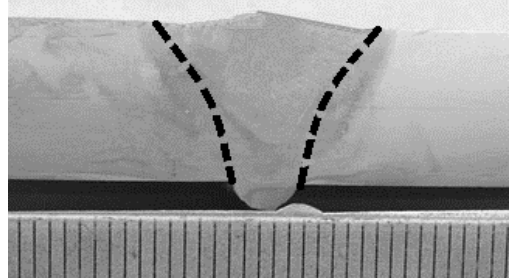

(f) M60 weld cross section

Fig. 3 The weld cross section of different welding methods and grove

As is shown in Fig.3, the weld reinforcement decreased with the increase of the groove angle under the condition of little change in the welding parameters. The H30 and M40 weld penetration was in good condition, with smooth weld reinforcement transition, and the required number of layers was also less, as is shown in Fig.3a and 3b. From the observation of macro morphology of the above two kinds of welded joints (Fig. 4), it can be seen that the surfaces of H30 and M40 welds were relatively smooth, without the defects like undercut and crack, which indicated that the hybrid welding with $30^{\circ}$ groove angle and the MAG welding with $40^{\circ}$ groove angle were appropriate for the welding of the $12 \mathrm{~mm}$ thick atmospheric corrosion resistant steel SMA490BW. However, the hybrid welding had obvious advantages in the welding speed and heat input.
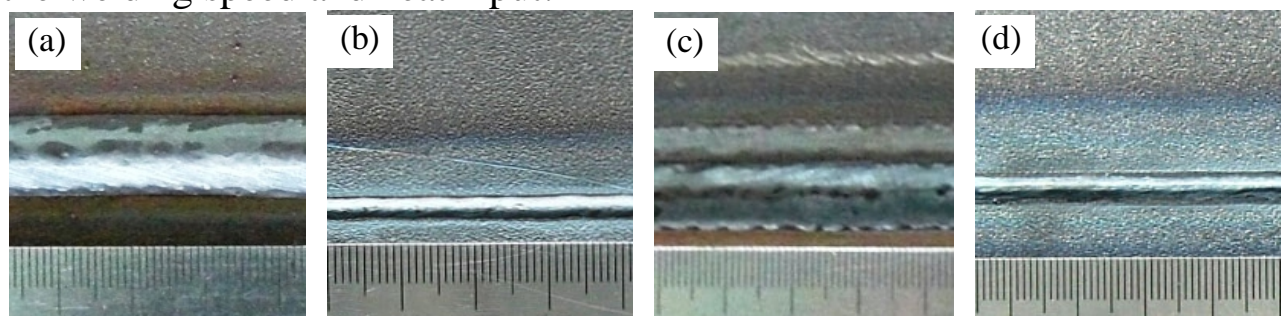

(a)MAG welding weld front profile with $40^{\circ}$ groove ; (b)MAG welding weld reverse profile with $40^{\circ}$ groove ; (c) Hybrid welding weld front profile with $30^{\circ}$ groove; (d) Hybrid welding weld reverse profile with $30^{\circ}$ groove.

Fig. 4 The weld macro forming with different welding methods and groove

Residual Stress Test. In order to analyze the effect of different welding methods and grooved on residual stress distributions of the joints, the residual stress of the welded joints was tested by X-ray method. Fig. 5 shows the distributions of residual stress test points, and the results are shown in Fig.6. 


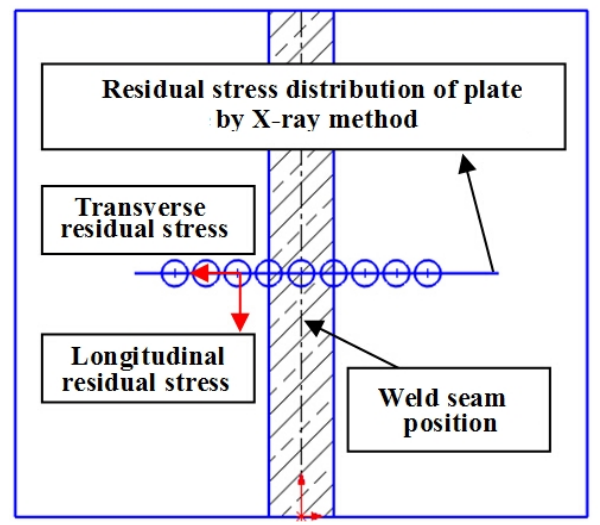

Fig. 5 Schematic of residual stress test by X-ray method
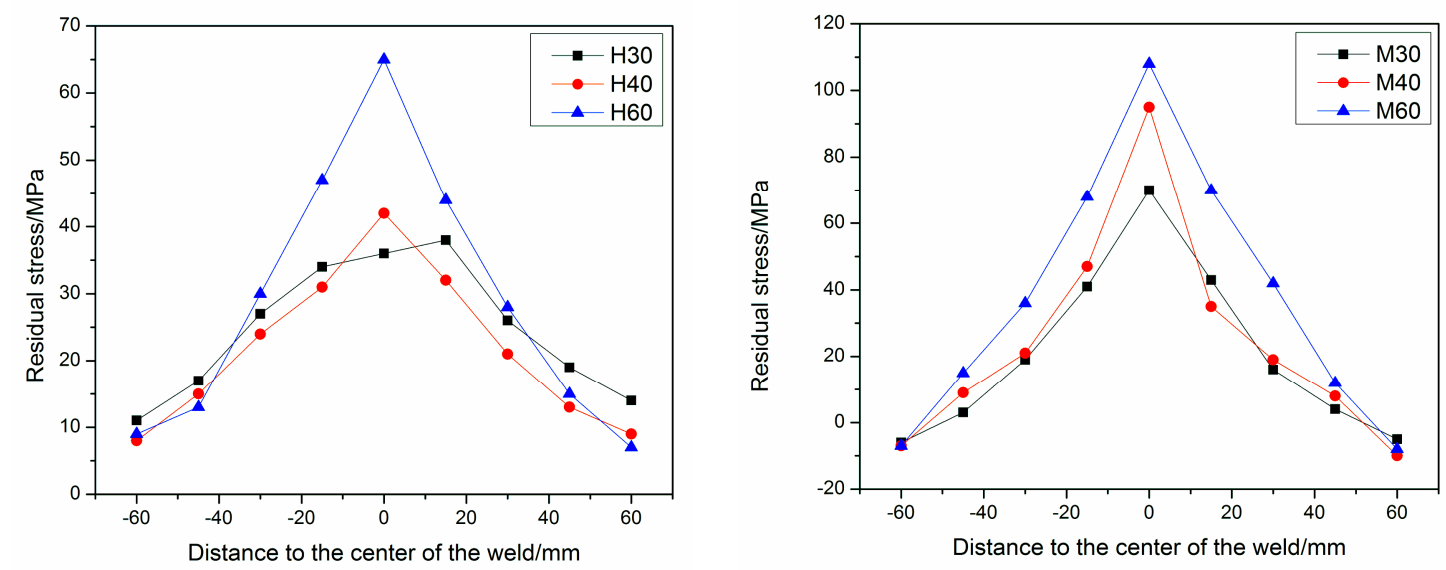

( a )Transverse residual stress distributions of laser-MAG hybrid welding ( b )Longitudinal residual stress distributions of laser-MAG hybrid welding
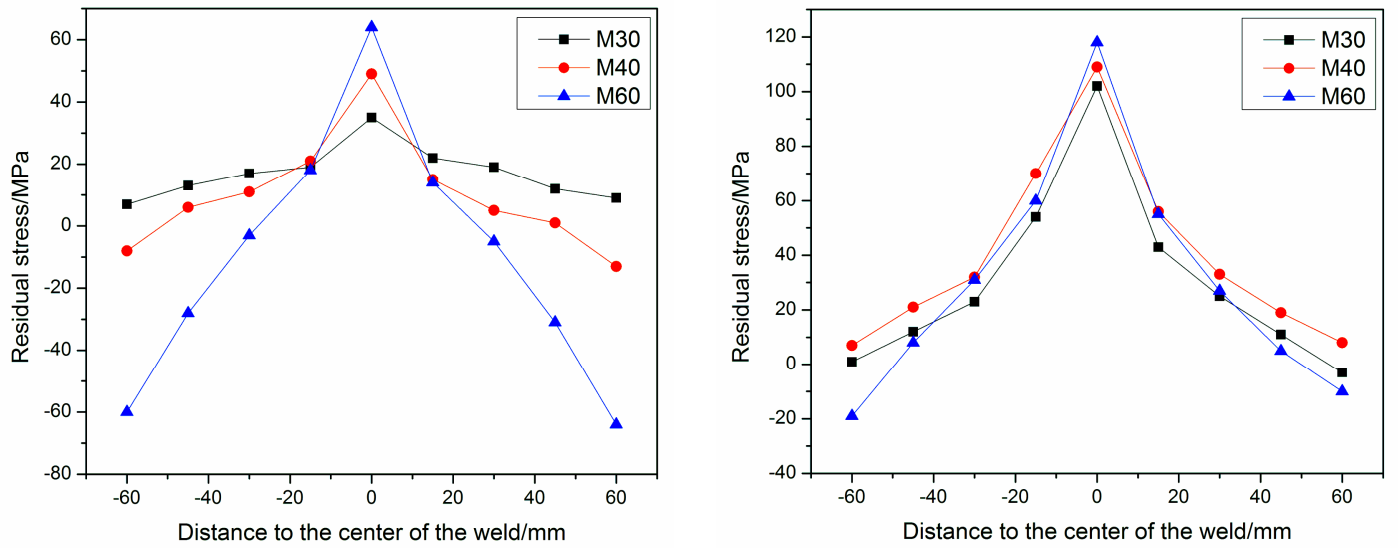

( c ) Transverse residual stress distributions of MAG welding ( d ) Longitudinal residual stress distributions of MAG welding

Fig. 6 Residual stress distributions of laser-MAG hybrid welding and MAG welding

Welding was a process of uneven heating. The longitudinal shrinkage of the weld will produce the longitudinal residual stress. Besides, the transverse shrinkage and longitudinal shrinkage of the weld zone and plastic deformation zone will produce the transverse residual stress together.

As is shown in Fig 6a and 6c, the transverse residual stress near the weld zone was tensile stress, while the transverse residual stress far away from the weld zone was compressive stress, and the value of transverse tensile residual stress in the middle of the weld was the maximum. With the increase of the groove angle, the weld metal which was needed to fill increased, as well as the welding heat input. Therefore the transverse residual stress of weld increased with the increase of groove angle. According 
to the Fig. $6 \mathrm{~b}$ and $6 \mathrm{~d}$, the distribution law of longitudinal residual stress of the weld was the same as that of transverse residual stress. The value of the longitudinal residual stress in the center of the weld was the largest, and from center to both sides of the weld, the longitudinal residual stress of the weld was gradually changing from the tensile stress to compressive stress. The weld's longitudinal residual stress of different groove angles was compared, and it was shown that with the increase of the groove angle, the weld metal which was needed to fill increased, therefore the shrinkage of the weld increased, as well as the longitudinal residual stress.

In general, the residual stress level of laser-MAG hybrid welding was less than that of MAG welding, because the laser-MAG hybrid welding had higher welding speed and less fill metal was required so that the welding deformation of the hybrid welding was smaller, and the residual stress level was decreased.

\section{Microstructure and Hardness Test}

Microstructure analysis. The metallographic structures of H30 and M40 typical joints are shown in Fig.7. As Fig.7a shows the joints' morphology of laser-MAG hybrid welding which was observed in low-power. The joint included the weld zone, heat affected zone and base metal. Besides, the heat affected zone can be subdivided into overheated zone, normalized zone and incomplete recrystallization zone. The distribution of the MAG welding joints was similar to that of hybrid welding joints.
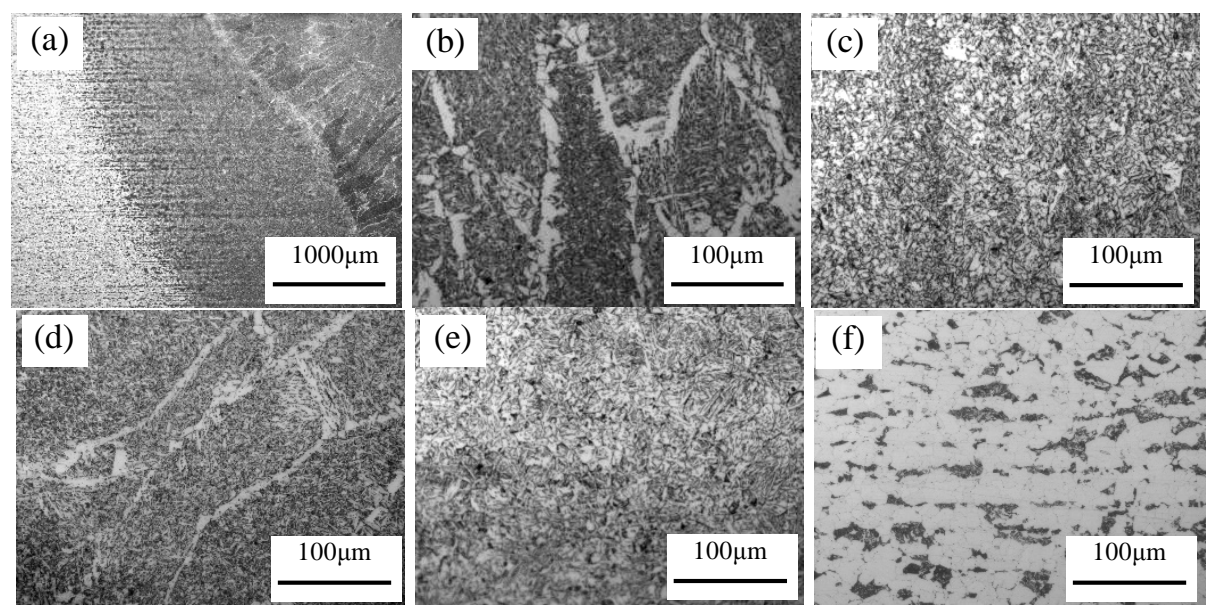

(a) Joints' morphology of hybrid welding in low-power; (b) MAG welding zone; (c) Normalized zone of MAG welding;(d) Weld zone of hybrid welding; (e) Normalized zone of hybrid welding (f) Base metal

Fig. 7 The joints' microstructure of MAG welding and laser-MAG hybrid welding

The weld microstructure shown in Fig. $7 \mathrm{~b}$ and $7 \mathrm{~d}$ was the ferrite band along the grain boundary, and the carbide-free bainite grew into the crystal; in the crystal, there were acicular ferrite, ferrite side-plate and pearlite. In process of crystallization, the ferrite band separated out along the grain boundary of austenite, and the ferrite side-plate grew into the crystal as side-plate from flank of the grain boundary of austenite. In the original austenite grain, there was the acicular ferrite, which changed into pearlite after the cooling of original austenite. By the comparison of Fig. $7 \mathrm{~b}$ and $7 \mathrm{~d}$, it can be seen that the ferrite band of MAG welding was more butt, because of the larger heat input of MAG welding.

By comparing the Fig.7c and 7e, it can be seen that the normalized zone microstructure of 2 kinds of joints were both ultrafine ferrite and pearlite, and the distribution of the normalized zone microstructure welded by hybrid welding was more uniform. The base metal microstructure is shown in Fig.7f, which were equiaxed ferrite and pearlite. As the supply state of base metal was in the condition of hot rolling, the dendrite segregation and impurities were elongated in the processing, showing the characteristics of black banded structure. 
Hardness Test. The hardness tests to the H30 joints and M40 joints were conducted, and the test results are shown in Fig.8. From the hardness curve, it can be seen that the change of the hardness of the two kinds of joints was almost the same. The hardness value of base metal was the lowest, only about $165 \mathrm{HV}$ because there was no phase transition in the base metal during the welding process, and the microstructure was still composed by pearlite and ferrite. The weld zone was composed by acicular ferrite, ferrite band and pearlite so that the value of hardness was relatively high. In the whole joint, the value of hardness of the coarse grain zone in the heat affected zone was the highest, because such zone was composed by widmanstatten microstructure. The high hardness was caused by the shear formation mechanism of widmanstatten microstructure. However the plasticity and toughness of widmanstatten microstructure was poor, the coarse grain zone was the relatively weak zone in the whole joint; the value of hardness of normalized zone was lower than that of coarse grain zone, because its microstructure was fine and uniform ferrite; In the incomplete phase transformation zone, the characteristics of the base metal were retained by some microstructure due to the incomplete phase transformation, and the hardness value was lower than the normalized zone but slightly higher than the base metal.

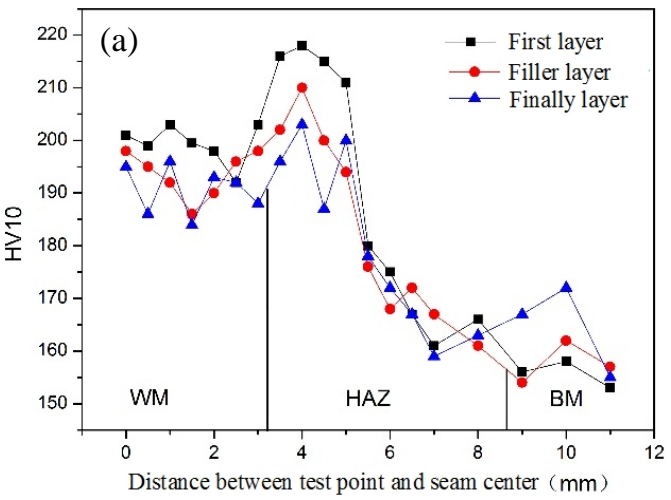

(a)MAG welding

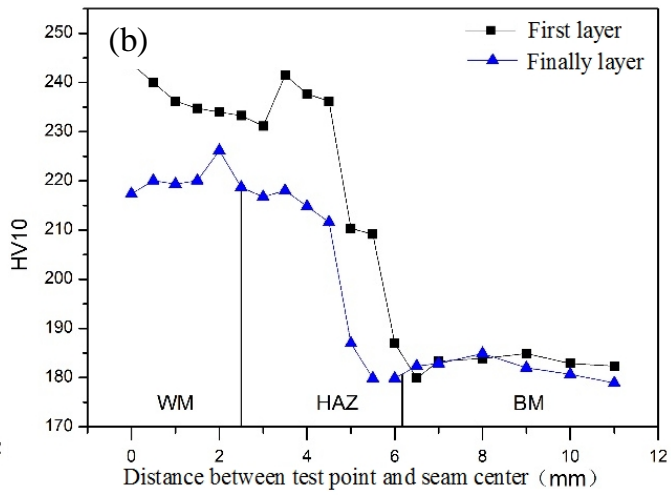

(b) laser-MAG hybrid welding

Fig. 8 Hardness curve of typical joints

By comparing the Fig. $8 \mathrm{a}$ and $8 \mathrm{~b}$, it can be seen that the width of the heat affected zone of the joint welded by MAG welding was about $6 \mathrm{~mm}$, while the width of the heat affected zone of the joint welded by laser-MAG hybrid welding was only about $3.5 \mathrm{~mm}$, which was relative to the high speed and small welding heat input of the hybrid welding. The highest hardness value of hybrid welding was higher than that of MAG welding, because of the higher cooling speed of joints welded by hybrid welding.

\section{Conclusions}

1. The optimum parameters of laser-MAG hybrid welding of $12 \mathrm{~mm}$ thick atmospheric corrosion resistant steel SMA490BW were obtained ;

2. The residual stress distributions of the two kinds of joints were compared, and the value of residual stress of the laser-MAG hybrid welding joint was smaller than that of MAG welding.

3. The microstructure of $12 \mathrm{~mm}$ thick corrosion resistance steel SMA490BW joint welded by laser-MAG hybrid welding was finer than that of MAG welding, and the width of the heat affected zone was smaller than that of MAG welding.

\section{References}

[1] G. Jin. Study on microstructure and mechanical properties of the welded joints of bogie frame material in carriage, D. Da lian Jiaotong university. 2007.

[2] Ming Hong, Qiang Wang, Zhongqing Su. In situ health monitoring for bogie systems of CRH380 train on Beijing-Shanghai high-speed railway , J. Mechanical Systems and Signal Processing, 2014, 45(2): 378-395. 
[3] Z.X. Wang. Measures to improve the load carrying capacity of the main frame and the bogie frame of the diesel locomotives, J. Foreign Diesel Locomotive. 2004, 4(6): 78-83.

[4] H.J. Liu. Analysis of residual stress and deformation for side beam on bogie, D. Southwest JIAOTONG university.2012.

[5] Y.L. Liao. Research on fatigue of articulated bogie frame, D. Southwest JIAOTONG university.2009.

[6] Shu Zhen, Zhenzhen Duan, Daqian Sun. Study on microstructures and mechanical properties of laser-arc hybrid welded S355J2W+N steel, J. Mechanical Systems and Signal Processing, 2014, 59: $11-18$.

[7] Y.B. Chen. Technology of modern laser welding, M. Science Press. Beijing, 2005, 3(7): 147-152.

[8] X.C. Yuan. Research and application of laser arc hybrid welding technology, J. Welding Technology. 2010, 4(8): 5-9.

[9] S.C. WU. Laser welding of aluminum alloy and performance evaluation, M. National Defend Industry Press. Beijing, 2014, 1: 93-94.

[10] Y.H. Zhang. Principle of welding structure, M. Beihang University Press. Beijing, 2011, 1: 35-37. 